Original article

\title{
Serum low replacement medium versus serum rich replacement medium for production of Anti-Schistosoma Monoclonal antibody: A comparative study
}

\author{
Faten S. Mahmoud ${ }^{\mathrm{a}}$, Zeinab A. Demerdash ${ }^{\mathrm{a}}$, Sherihan M. Elmotawakel ${ }^{\mathrm{a}}$, Salwa Hassan ${ }^{\mathrm{a}}$, \\ Mohamed Hendawy ${ }^{\mathrm{b}}$, Shimaa A. Atta ${ }^{\mathrm{a}, *}$, Shereen M. Shawky ${ }^{\mathrm{c}}$, Engy M. Alkhateeb ${ }^{\mathrm{c}}$, \\ Hanaa I. Hassanin ${ }^{\mathrm{a}}$ \\ a Immunology Department, Theodor Bilharz Research Institiute, Egypt \\ ${ }^{\mathrm{b}}$ Parasitology Department, Theodor Bilharz Research Institute, Egypt \\ ${ }^{\mathrm{c}}$ Clinical and Chimical Pathology Department, Faculty of Medcine, CairoUniversity, Egypt
}

\section{A R T I C L E I N F O}

\section{Keywords:}

Monoclonal antibody

Replacement media

Schistosomiasis

Hybridoma

Soluble egg antigen

\begin{abstract}
A B S T R A C T
Objective: to assess the production of Anti-Schistosoma Monoclonal Antibodies by growing IgM producing hybridoma cell line in serum low medium and to evaluate their diagnostic potential to replace the old conventional method in animal ascetic fluid.

Methods: Highly reactive and specific IgM MAb secreting hybridoma cell line to S. mansoni SEA was cultured in three different media; serum rich replacement medium (conventional), serum low replacement medium (SLRM) and serum free replacement medium (SFRM).

Results: Cell count and viability were better in conventional medium and SLRM than SFRM. The lower detection limit of the assay Mab of SLRM culture was $1.1 \mathrm{ng} / \mathrm{ml}$ of S. mansoni SEA. SFRM was excluded because of the low concentration and reactivity. MAb was tested against 34 human samples. Sensitivity and specificity of the assay for each were $92 \%$ and specificity $90 \%$ for SLRM respectively. The diagnostic efficacy of the assay was $94 \%$. Conclusions: the production and diagnostic efficacy of antischistosomal MAbs was comparable on usage of either in vitro cell culture supernate in SLRM or conventional media.
\end{abstract}

\section{Introduction}

Cell culture technology has allowed the production of a great diversity of biological substances for investigational and diagnostic purposes. One of the most important cell culture technology-based products is monoclonal antibodies ${ }^{1,2,3}$ Monoclonal antibodies (MAbs) constitute more than $25 \%$ of total biotechnology production ${ }^{4,5,6}$ At the beginning, the cell culture medium used for MAbs production contained animal products such as serum, albumin, and growth factors. Serum containing culture systems are becoming undesirable for small-scale culture as well as large-scale processes in industry due to high cost, inconsistency from batch to batch and increased liability of viruses, bacteria, mycoplasma and prions contamination and the most important being the high protein load, which can hinder product purification. Considering all these reasons, several commercial serum-free media specific for different cell lines have been developed ${ }^{1,7,8}$ The antischistosomal MAbs raised in Conventional medium were extensively evaluated for their efficiency in immunodiagnosis of active schistosomal infection and monitoring of chemotherapy effectiveness at the Immunology Laboratory, TBRI. ${ }^{9-11}$ However, MAbs raised in ascitic fluid were faced with purification difficulties and some sort of cross reactivity. The use of $\mathrm{T}$ culture flasks for large scale production using serum free media would help to alleviate theses difficulties. The production of MAbs by in vitro hybridoma cells culture, although tried by some investigators ${ }^{8,12,13}$, still needs further trials to be evaluated. The aim of this work is to study the efficacy of serum low medium for in vitro production of Anti-Schistosoma Monoclonal antibodies by hybridoma cell culture as compared to serum rich medium, and their diagnostic potentials.

\section{Materials and methods}

\subsection{Ethical statement}

This study was reviewed and approved by the ethics committee of Theodor Bilhariz Research Institute (TBRI) and methods including

\footnotetext{
* Corresponding author. Immunology Lab, Theodor Bilharz Research Institute, Kornish El Nil street, Giza, Imbaba 30, Egypt.

E-mail address: attashimaa@yahoo.com (S.A. Atta).
} 
samples collection were carried out in accordance with relevant guidelines and regulations.

\subsection{Preparation of culture media}

a Conventional medium: Conventional medium contains Roswell Park Memorial Institute (RPMI)- 1640 medium pH 7.2-7.4 (Sigma Chem. Co., St. Louis, MO, USA) supplemented with $20 \mathrm{~mL} / \mathrm{L}$ HEPES, $3 \mathrm{~mL} /$ L Na bicarbonate $7.5 \%, 0.1 \mathrm{~mL} / \mathrm{L}$ penicillin $(10,000$ units $/ \mathrm{ml})$ / streptomycin $(10 \mathrm{mg} / \mathrm{ml}$ ) (Sigma) in $0.9 \%$ sodium chloride and $10 \mathrm{ml}$ L-glutamine and $20 \%$ fetal calf serum (FCS) heat inactivated at $56^{\circ} \mathrm{C}$ for $30 \mathrm{~min}$ in water bath to deactivate the complement-system cytolytic proteins according to Kolher and Milstin. ${ }^{14}$

b Serum free replacement medium (SFRM): $\mathrm{Nu}$ serum TM culture medium (BD Bioscience, UK), is industrially used for cultivation of different cell lines. This growth medium is supplemented with essential components used as replacement for fetal bovine serum such as Ham's F-12 Nutrient Mixture, Dulbecco's Modified Eagle's Medium (DMEM), specific factors, like hormones and growth factors, fatty acids and lipids, and vitamins and trace elements.

c Serum low replacement medium (SLRM): Contains $2.5 \%$ FCS in serum free replacement medium; selected after pilot trials at a range of $2.5-20 \%$ of FCS.

\subsection{Revival and propagation of hybrid cells}

Hybridoma cell lines secreting MAbs were prepared at the Immunology Department of TBRI and preserved in liquid nitrogen. The hybrid cells were revived and their reactivity was measured by ELISA. The highly reactive cells to $\mathrm{S}$. mansoni and non reactive to Fasciola hepatica or Echinococcus granulosus antigens were selected.

\subsection{Adaptation of hybrid cells}

Cells were cultured in T culture flask and adapted in either SLRM and SFRM. The supernatant was collected and used for testing the activity of MAbs (a glycoprotein recognizes repetitive epitope on $\mathrm{S}$. mansoni SEA at a molecular weight region 27 to $80 \mathrm{kD}$ ) against Schistosama antigen and crossreactivity against different parasitic antigens by indirect ELISA method. Cells were counted and viability was determined using the conventional method of trypan blue exclusion. ${ }^{15}$

\subsection{Indirect ELISA method}

Wells of polystyrene microtitre plates (96-flat bottomed wells, M 129 a Dynatech) were coated with $100 \mu \mathrm{l} /$ well of S. mansoni SEA or other parasitic antigens (Fasciola hepatica and Echinococcus granulosus) at a concentration of $30 \mu \mathrm{g} / \mathrm{ml}$ carbonate buffer $\mathrm{pH}$ 9.6. The absorbance was measured at $492 \mathrm{~nm}$ using ELISA reader (Bio-Rad microplate reader, Richmond, Co.).

\subsection{Purification and conjugation of MAbs}

MAbs were previously determined to be of IgM class and they were purified from supernatant by euglobulin precipitation. ${ }^{16}$ The final precipitate was dissolved in a suitable amount of 0.2 M PBS, pH 7.2. The antigen detecting MAb was conjugated to horse radish peroxidase (type IV; Sigma) according to Tijssen and Kurstak. ${ }^{17}$

\subsection{Determination of the lower detection limit of the MAb by indirect ELISA}

Wells of polystyrene microtitre plates (96-flat bottomed wells, M 129 a Dynatech) were coated with serial dilutions of $S$. mansoni soluble egg antigens (SEA) $(0.5-9 \mathrm{ng} / \mathrm{ml})$ in $0.1 \mathrm{M}$ carbonate buffer $\mathrm{pH}$ 9.6. The absorbance was measured at $492 \mathrm{~nm}$ using ELISA reader (Bio-Rad microplate reader, Richmond, Co.).

\subsection{Human subjects}

All methods were carried out in accordance with relevant guidelines and regulations. This study was reviewed and approved by the ethics committee of Theodor Bilhariz Research Institute.

Thirty four subjects were chosen for schistosomiasis testing according to their history for CSA assay. Their history was taken and a clinical sheet was done for them including information about results of analysis of their excreta by parasitological examination. Of them 24 subjects were excreta positive (S. mansoni eggs in their stool) and 10 subjects were excreta negative. Ten healthy individuals from medical personel at TBRI served as negative controls for S. mansoni eggs. Blood samples were withdrawn from each individual and sera were separated, aliquoted and stored at $-20 \mathrm{C}$. All individuals were subjected to CSA assay using MAb produced either by in vitro cultured supernate in SLRM or conventional media. Detection of CSA in sera by sandwich ELISA was performed according to Demerdash et al. (1995). ${ }^{18}$

\subsection{Statistical analysis}

Data were analyzed using package SPSS version 18.0 for windows (SPSS Inc., Chicago, IL). Demographic and laboratory data were considered statistically significant. Spearman's rank correction (r) was done. The mean patient serum between different types of the diagnostic accuracy and healthy controls were compared with one-way analysis of variance (ANOVA). At a $\mathrm{P}$ value $\leq 0.05$ differences were considered statistically significant. The Dunkan test was used to analyze the difference between two groups.

\section{Results}

\subsection{Adaptation of hybrid cells}

Hybridoma cell count and viability were comparable when using conventional medium and SLRM. They were better than those cultured in SFRM (Table 1).

Culturing in SFRM was excluded due to decrease in the cell count and viability as well as having the lowest Schistosoma MAb reactivity compared to other media (Fig. 1).

\subsection{The lower detection limit of schistosomal antigen}

Two standard curves were set up by using MAb of Conventional medium and SLRM origin. Optical density (OD) readings were plotted against the concentration of S. mansoni SEA. Both standard curves showed the lower detection limit of $1.1 \mathrm{ng} / \mathrm{ml}$ of schistosomal antigen (Fig.2).

Table 1

Comparison of viability and total cell count of hybridoma cell line in three different media.

\begin{tabular}{|c|c|c|c|}
\hline & Conventional medium & Serum free replacement medium & Serum low replacement medium \\
\hline Viability (\%) & 86 & 80 & 85 \\
\hline Total count $\left(\times 10^{6}\right)$ & 18.5 & 17 & 18 \\
\hline
\end{tabular}




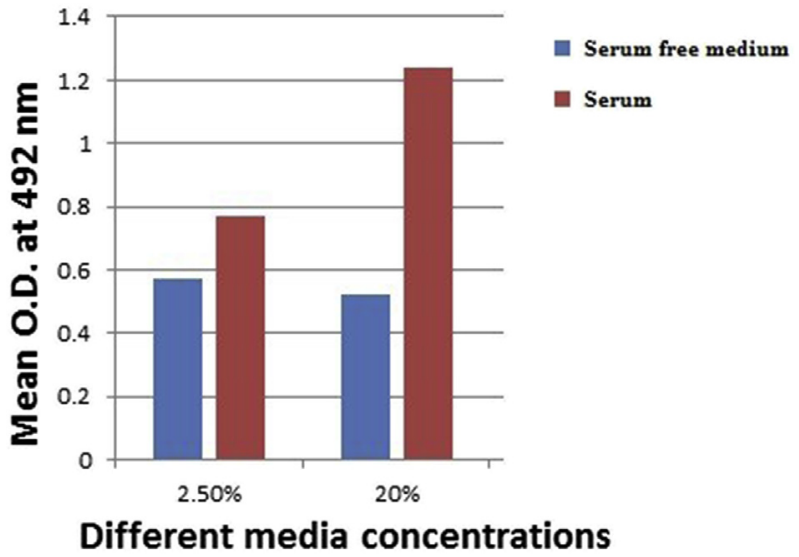

Fig. 1. The reactivity of antischistosomal MAbs produced in culture supernate of SFRM and SLRM (2.5\% serum) or conventional medium (20\% serum). Abb. Reactivity of antischistosomal MAbs: Reactivity of antischistosomal MAbs produced in culture media: SLRM or conventional was tested against SEA by indirect ELISA (Fig. 1).

\subsection{Detection of CSA in sera by sandwich ELISA}

Results are presented as CSA level calculated from the standard curve of SEA. The cut off value was determined as the mean OD reading negative controls $+2 \mathrm{SD}$ of the mean and was equal to 0.21 for MAb of SLRM and conventional medium. Therefore all studied sera showing O. $D$ reading $\geq 0.21$ were considered positive for CSA and those $<0.21$ were negative for CSA.

CSA level was detected in the 23 stool positive cases (out of 24) and not detected in the 9 stool negative cases (out of 10) from the 34 tested sera, and the sensitivity of antigen assay was $95 \%$ by sandwich ELISA using MAb produced in conventional medium. On the other hand, 22 positive and 9 negative out of the 34 tested subjects were obtained for CSA detection using MAb in SLRM with a sensitivity of $92 \%$. Furthermore, percent specificity for CSA was $90 \%$ for MAb of both conventional medium and SLRM origin. The diagnostic efficacy of the assay was $94 \%$ and $91 \%$ of conventional medium and SLRM respectively (Fig. 3\&Table 2). The difference between them was not statistically significant.

Sensitivity, specificity and diagnostic efficacy using IgM MAb produced in conventional medium were comparable to those of the culture supernate in SLRM (Table 2).

Twenty three patients were positive for both CSA using MAbs raised in conventional medium and excreta. 22 patients were positive for both CSA using MAbs raised in SLRM medium and excreta (True Positive).

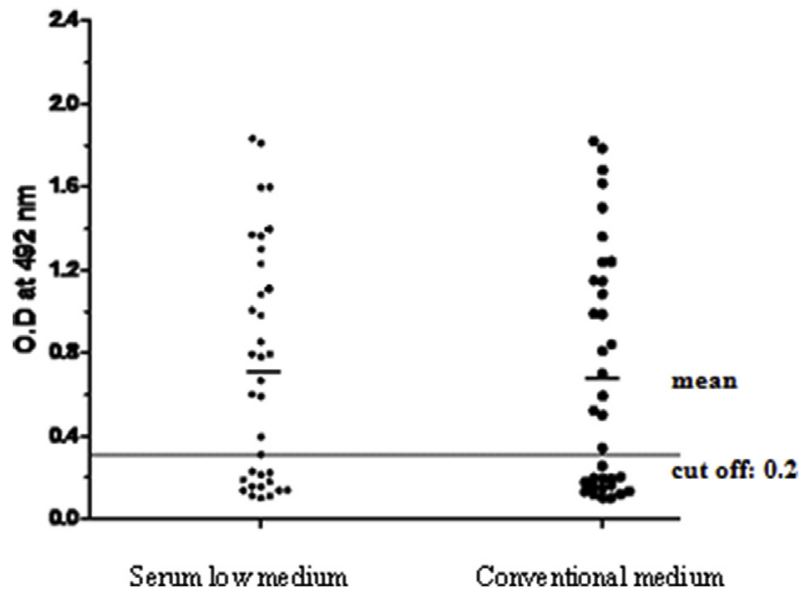

Fig. 3. Level of CSA in serum samples of S. mansoni-infected patients $(n=34)$ detected by sandwich ELISA measured at $492 \mathrm{~nm}$ using MAbs produced from culture supernatant in SLRM or in ascetic fluid.

Table 2

Sensitivity, specificity and diagnostic efficacy of parasitological and CSA results of patients using MAbs of conventional medium and serum low medium.

\begin{tabular}{lll}
\hline Media type & MAb of Conventional medium origin & MAb of SLRM origin \\
\hline Sensitivity & $95 \%$ & $92 \%$ \\
Specificity & $90 \%$ & $90 \%$ \\
Diagnostic efficacy & $94 \%$ & $91 \%$ \\
\hline
\end{tabular}

Nine patients were negative according to both CSA using MAbs raised in SLRM medium and excreta while 7 patients were negative for both CSA using MAbs raised in conventional medium and excreta (True Negative).

False negative result was detected in 3 patient; negative excreta and positive CSA using MAbs raised in conventional medium in 1 sample and negative excreta and positive CSA using MAbs raised in SLRM medium in 2 samples. ELISA failed to detect CSA in 4 samples while the excreta were positive; 1 with using MAbs raised in conventional medium and 3 using MAbs raised in SLRM medium.

To summarize; true positive results were obtained in 23 cases when using conventional media and 22 when using SLRM. True negative results were obtained in only 7 patients when using conventional media and 9 when using SLRM. False negative results appeared in 1 sample using conventional media and 2 when using SLRM. False positive results appeared in 1 case using conventional media and 3 using SRLM.
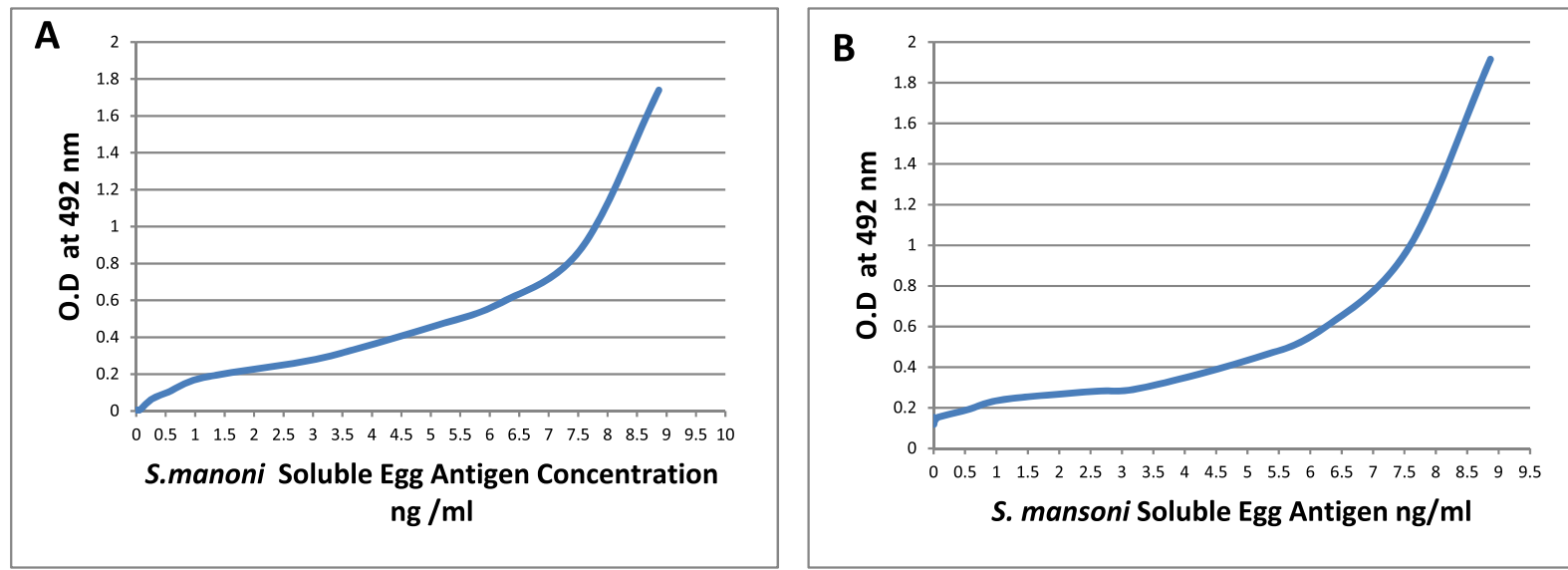

Fig. 2. The standard curve of S. mansoni SEA at different concentrations (ng/ml) plotted using anti-schistosomal IgM MAb (6D/6F) produced in conventional medium (A) or produced in SLRM (B) by an indirect ELISA test. 
Table 3

Comparison between parasitological and CSA findings of the thirty four subjects studied.

\begin{tabular}{|c|c|c|c|c|}
\hline CSA & Positive & & Negative & \\
\hline Excreta & $\begin{array}{l}\text { MAb/Conventional } \\
\text { medium }\end{array}$ & $\begin{array}{l}\text { MAb/ } \\
\text { SLRM }\end{array}$ & $\begin{array}{l}\text { MAb/Conventional } \\
\text { medium }\end{array}$ & $\begin{array}{l}\text { MAb/ } \\
\text { SLRM }\end{array}$ \\
\hline Positive & $23(\mathrm{TP})^{*}$ & 22 (TP) & $1(\mathrm{FP})^{*}$ & 3 (FP) \\
\hline Negative & $1(\mathrm{FN})^{*}$ & $2(\mathrm{FN})$ & $9(\mathrm{TN}) *$ & $7(\mathrm{TN})$ \\
\hline
\end{tabular}

*TP: true positive ${ }^{*} \mathrm{TN}$ : true negative ${ }^{*} \mathrm{FP}$ : false positive ${ }^{*} \mathrm{FN}$ : false negative.

Analysis of results of CSA against the parasitological findings is shown in Table 3.

\section{Discussion}

The detection of CSAs has been shown to be a sensitive and specific alternative to parasitology and antibody detection methods in the diagnosis of active Schistosoma infection. The use of MAbs in CSA assays has greatly improved their specificity and sensitivity. ${ }^{18,19,20,21}$ The need of serum-free media for the production of MAbs by hybridoma cells has been clearly established by many authors. ${ }^{2,7,8}$ There are many important problems associated with serum-containing media, the most important being the high protein load, which makes product purification more difficult, the high cost serum and the risk of contamination. Other problems are the undefined composition of serum as well as the production method of fetal serum, which is also ethically questionable. As a consequence, a lot of effort has been devoted in recent years to replace serum in media for the cultivation of hybrid cells ${ }^{1,7,8}$ In the current study, IgM MAb $(6 \mathrm{D} / 6 \mathrm{~F})$ that is highly reactive and specific to S. mansoni SEA was selected from a panel of MAbs by indirect ELISA and cultured in conventional medium. Hybrid cells $(6 \mathrm{D} / 6 \mathrm{~F})$ were cultured in conventional medium. After propagation of hybrid cells in Tculture flasks, they were passaged in three different media; conventional, SLRM and SFRM. Hybridoma cell count and viability were comparable when using conventional medium and SLRM. They were better than those cultured in SFRM. The reduction of serum concentrations over time can increase the probability of successful adaptation to low-serum or serum free media by allowing the self-adjustment of the cells to the environment, with the time required depending on the cell line and the composition of the media. Hybridoma cell lines cultured in serum low or free media continued to secret MAbs at level achieved in the presence of serum. ${ }^{21} \mathrm{Nu}$ serum TM replacement-used in our work-has been used successfully on a large variety of human and animal cell types. Examples of cell types growing in $\mathrm{Nu}$ replacement medium include HepG2 human hepatocellular carcinoma, human bladder cancer cells and hybridoma cell lines. ${ }^{1}$ Reactivity of antischistosomal MAbs produced in conventional medium and in culture supernate of SLRM were comparable when tested against SEA by indirect ELISA. Therefore, supernatants of SLRM and conventional medium were collected and purification of IgM MAbs was done by euglobulin precipitation method. Culturing in SFRM was excluded due to decrease in cell count and viability as well as having the lowest Schistosoma MAb reactivity compared to other media. It is possible that there are residual hormones and growth factors from the serum which helped to support the integrity of cells. ${ }^{21}$ In the present study, MAb (6D/6F) was employed in sandwich ELISA for CSA detection in a number of subjects. This MAb/ELISA system reached a lower detection limit of $1.1 \mathrm{ng} / \mathrm{ml}$ of $\mathrm{S}$. mansoni SEA in both standard curves for MAb $(6 \mathrm{D} / 6 \mathrm{~F})$ cultured in conventional medium or SLRM. A similar CSA detection limit was reached by Demerdash et al., ${ }^{18}$; and EL-Mohandes et al., ${ }^{22}$ showing a lower detection limit of $1 \mathrm{ng} / \mathrm{ml}$. In the current study, CSA level was detected in 23(out of 24) stool positive cases and was undetectable in 9 (out of 10) stool negative cases of the sera of studied subjects and the sensitivity of antigen assay was $95 \%$ by sandwich ELISA using MAb $(6 \mathrm{D} / 6 \mathrm{~F})$ produced in conventional medium. On the other hand, 22 cases (out of 24) were CSA positive and 9 (out of 10) were CSA negative of the studied subjects for CSA using MAb produced in SLRM with a sensitivity of $92 \%$. Furthermore, percent specificity for CSA was $90 \%$ for both Conventional medium and SLRM. The diagnostic efficacy of the assay was $94 \%$ and $91 \%$ respectively. The difference between them was not statistically significant. Therefore, sensitivity, specificity and diagnostic efficacy using MAbs produced in conventional medium were comparable to those of the culture supernate in SLRM. The sensitivity rate for antigen detection assay, ranging from $86 \%$ to $98 \%$ has been reported using S. mansoni MAbs. ${ }^{10,23}$ The specificity of those assays was in the $80 \%-96 \%$ range. In this study, there was two false positive case that was excreta negative and CSA positive using serum low medium and conventional medium. It is to be noted that all patients were examined for Schistosoma eggs in urine and stool only once and none of them performed recto-sigmoidoscopy. This finding supports the use of CSAassay as an alternative or complement to other existing diagnostic methods. In conclusion, our data demonstrate that the diagnostic efficacy of antischistosomal MAbs was comparable when produced by using either in vitro cell culture supernate in SLRM or conventional media.

The development and optimization of SLRM to be used in special cell culture is to be encouraged particularly in large scale production of MAbs as an alternative to the method of their production in ascitic fluid in BALB/c mice. In spite that SLRM is of less cost and higher production yield, still its further enrichment to cope better with the cell culture requirements is recommended.

\section{Support}

This work was funded by project $4 \mathrm{~K}$ internal project, Theodor Bilharz Research Institute, PI; Prof. Dr. Faten Salah Mahmoud.

\section{Declaration of competing interest}

There are no Conflicts of Interest of any author/contributor. The manuscript has been read and approved by all the authors.

\section{Acknowledgment}

The authors would like to thank Dr. Houda Abou-Taleb, lecturer in Enviroment Research Department, TBRI, for her effort during the statistical analysis of the study.

\section{References}

1. Hu W, Berdugo C, Chalmers JJ. The potential of hydrodynamic damage to animal cells of industrial relevance: current understanding. Cytotechnology. 2011;63(5):445-460https://doi.org/10.1007/s10616-011-9368-3 PMid: 21785843; PMCid: PMC3176934.

2. Conte F, Martins R, Cajaraville A, et al. Production of monoclonal antibody that recognizes Zika virus and other Flaviviruses in serum-free conditions. Monoclon Antibodies Immunodiagn Immunother. 2017;36(5):1-8.

3. Freshney RI. Culture of Animal Cells: A Manual of Basic Techniques. fifth ed. USA: willey-liss, Inc.; 2005:123.

4. Zhang C. Hybridoma technology for the generation of monoclonal antibodies. Methods Mol Biol. 2012;901:117-135. https://doi.org/10.1007/978-1-61779-931 $0 \_7$.

5. Lun Y, Cheng J, Zhang Y. Cloning, expression and identification of the gene of human scFv antibody against hepatitis B virus surface Ag. Acta Virol. 2006;50(3):195-200.

6. Schiel JE, Davis DL, Borisov O. American Chemical Society. State-Of-The-Art and Emerging Technologies for Therapeutic Monoclonal Antibody Characterization. Washington (DC, Oxford): American Chemical Society, Oxford University Press; 2014.

7. Rodrigues ME, Costa AR, Henriques M, Cunnah P, et al. Advances and drawbacks of the adaptation to serum free culture of CHO-K1for monoclonal antibody production. Appl Biotechnol. 2013;169(4):1279-1291.

8. Valdés R, Aragón H, González M, et al. Mouse hybridoma cell culture in a protein-free medium using a bio-mimicking fish-tail disc stirred bioreactor. Biol Pr J. 2017;16(1) https://doi.org/10.12665/J161.Valdes.

9. Mohamed SH, Mahmoud S, Rabee I. Immunolocalization of antigenic epitopes 
identified in different stages of Schistosoma mansoni life cycle of monoclonal antibodies. Kasr El Aini Med J. 2002;8:419-434.

10. Mohamed SH, Rabie IB, Diab TM. A monoclonal antibody-based latex agglutinationtest for detection of circulating schistosomal antigens in human schistosomiasis mansoni. New Egypt J Med. 2007;37:168-174.

11. Demerdash ZA, Mohamed SH, Hendawy M, et al. Monoclonal antibody based dipstick assay: Reliable field applicable technique for diagnosis of schistosoma mansoni infection using human serum and urine samples. Korean J Parasitol. 2013;51:93-98.

12. Chen Z, Ke Y, Chen Y. A serum free medium for hybridoma cell culture. Cytotechnology. 1993;11(3):169-174.

13. Stoll TS, Muhlethaler K, Stockar U, Marison IW. Systematic improvement of a chemically-defined protein-free medium for hybridoma growth and monoclonal antibody production. $J$ Biotechnol. 1996;45:111-123.

14. Kohler G, Milstein C. Continuous cultures of fused cells secreting antibody of predefined specificity. Nature. 1975;256(5517):459-499.

15. Walford RL, Gallagher R, Sjaarda J. Serological typing of human lymphocytes with immune serum obtained after homografting. Science. 1964;144(3620):868-870.

16. Garcia-Gonzalez M, Bettinger S, Ou S. Purification of murine IgG3 and IgM monoclonal antibodies by euglobin precipitation. J Immunol Methods. 1988;111:17-23.

17. Tijssen P, Kurstak P. Highly efficient and simple methods for preparation of peroxidase and active peroxidase antibody conjugates for enzyme immunoassays. Anal
Biochem. 1984;136(2):451-457.

18. Demerdash ZA, Mohamed SH, Shaker ZA, et al. Detection of circulating schistosomal antigens in serum and urine of schistosomiasis patients and assessment of cure by a monoclonal antibody. J Egypt Soc Parasitol. 1995;25(2):471-484.

19. Salah F, Demerdash Z, Shaker Z, et al. A monoclonal antibody against Schistosoma haematobium soluble egg antigen: efficacy for diagnosis and monitoring of cure of S. haematobium infection. Parasitol Res. 2000;86(1):74-80.

20. Salah F, El Bassiouny A, Rabie I, Demerdash Z, Roshdy M, Shaker Z. Human schistosomiasis haematobium: Effective diagnosis of active infection using a pair of monoclonal antibodies against soluble egg antigen. Parasitol Res. 2006;99(5):528-533.

21. Ajibola O, Gulumbe BH, Eze AA, Obishakin E. Tools for detection of schistosomiasis in resource limited settings. Med Sci. 2018;6(2):39. https://doi.org/10.3390/ medsci6020039.

22. El Mohandes MY, Mansour WA, Mahmoud FS. Circulating schistosomal antibodies, antigens and specific immune complexes as immunodiagnostic parameters for human schistosomiasis. Kasr El Aini Med J. 2001:405-420.

23. EL Bassiouny A, Salah F, Kamel M, Rabia I, Mansour W, Hassan S. Effective diagnosis of active schistosomiasis by a pair of IgG monoclonal antibodies against Schistosoma mansoni soluble egg antigen. Egypt J Med Sci. 2005;26(2):369-382. 